\title{
SPLITTING THE TOTAL EXERGY DESTRUCTION INTO ENDOGENOUS AND EXOGENOUS PARTS OF THE THERMAL PROCESSES IN A REAL INDUSTRIAL PLANT
}

\author{
UDC 621.1:536.7
}

\author{
Goran Vučković, Mića Vukić, Mirko Stojiljković, Miloš Simonović \\ University of Niš, Faculty of Mechanical Engineering, Niš, Serbia
}

\begin{abstract}
The total exergy destruction occurring in a component is not only due to the component itself (endogenous exergy destruction) but is also caused by the inefficiencies of the remaining system components (exogenous exergy destruction). Hence care must be taken in using the total exergy destruction of a component for making decisions to optimize the overall energy system. In this paper, a complex industrial plant is analyzed by splitting the component's exergy destruction into its endogenous part (the part resulting totally from the component's irreversibilities) and its exogenous part (resulting from the irreversibilities of the other components within the system). It is observed that the steam generator has the dominant effect. From the total exergy destruction in the steam generator, 1,097.63 $\mathrm{kW}$ or 96.95\% come from internal irreversibilities in the component, while the influence of other components on the loss of useful work in the steam generator is only $3.05 \%$.
\end{abstract}

Key Words: Exergy, Exergy Destruction, Endogenous, Exogenous, Industry

\section{INTRODUCTION}

With an increasing need to reduce the system waste impact on the environment and an ever increasing global demand for energy, especially in developing countries, it is becoming extremely important to develop even more accurate and systematic approaches for improving the design of energy systems [1].

Energy systems, i.e. industrial energy systems transforming some energy forms to others of which at least one is useful have been built since the eighteenth century. The continuously increasing complexity of the industrial systems has led to their construction and operation having a detrimental effect on natural resources and environment. It is,

Received August 23, 2015 / Accepted February 22, 2016

Corresponding author: Goran Vučković

University of Niš, Faculty of Mechanical Engineering Niš, A. Medvedeva 14, 18000 Niš, Serbia

E-mail:vucko@masfak.ni.ac.rs 
therefore, necessary to develop and apply methods that will help in design, construction and operation of highly efficient, environmentally friendly and economically viable systems [2].

Exergy as a term related to the quality of certain types of energy represents the part of energy that could be converted to any other form of energy, i.e. produce work. Exergy can be successfully used as a reference tool for evaluating energy consumption, user and society satisfaction, environmental hazard and economic cost. Exergetic analysis is a key element in analyzing and drawing up a plan for sustainable development [3].

Conventional exergetic analysis reveals irreversibility within each component of a plant, but it has some limitations [4]. Advanced exergetic analyses are needed in order to determine which part of the inefficiencies is caused by component interactions (i.e. the structure of the plant), and which part can be avoided through technological improvements of the plant [5].

The aim of this paper is to explicitly identify the exergy destruction and separate it into endogenous and exogenous exergy destruction, on the example of a real complex industrial plant.

\section{TECHNICAL DESCRIPTION OF A COMPLEX ENERGY SYSTEM}

The energy system in a representative factory, Fig. 1, consists of four parts: Energy supply sector, Factory 1, Factory 2 (F2) and Engineering department (ED).

The energy supply sector is a part of the factory complex where chemical and thermal treatment of water is being carried out while superheated steam is produced for the factory's own use and supply of all other consumers. Furthermore, in this section, compressed air and cooling water are prepared for the whole factory complex. The boiler produces superheated steam at the pressure of 10 bars, which is then distributed to factories 1 and 2, and partly reduced at lower pressures in accordance with the needs of consumers. In this paper, it is assumed that the fuel used is pure methane. Compressed air at pressure of 7 bars is prepared in the compressed air station where electricity is used to drive the compressors. Consumers of compressed air are Factory 1, Factory 2 and Engineering department.

Cooling water for factories 1 and 2 is prepared in the evaporative cooling tower. Hot water from factories 1 and 2 is pumped to the pool of hot water and then transported with pump 3 towards the cooling tower. A spray jet of cooling water, transported from the pool of hot water, spreads over the tube bundle of evaporative heat exchangers and is collected into the reservoir. Forced air flow is provided with the centrifugal ventilator, while water drops removal within the air flow is prevented with the droplet eliminator. The cooled water is collected and transported with the pump 4 to consumers in factories and the compressed air station.

Factory 1 is the largest consumer of energy in the whole complex and it is supplied with energy using the superheated steam at the pressure of 10 bars, compressed air and cooling water. Electric energy is provided from a separate transformer station.

Consumers in the factory use the steam at pressures of 10 and 4 bars. The condensate is collected in the condensate tank 2, and then transported with the pump 6 to the condensate tank 1 . The sanitary hot water is prepared in the tank with the capacity of 3000 liters. The primary fluid is steam at 4 bars which, after energy is delivered to the secondary fluid, condenses and goes to the condensate tank 2 . The secondary fluid is water with the temperature regime $12 / 60^{\circ} \mathrm{C}$. 
Thermal comfort in the manufacturing hall during winter months is maintained with convectors. The steam at 4 bars completely condenses in the convectors and the condensate is transported to the condensate tank 2 .

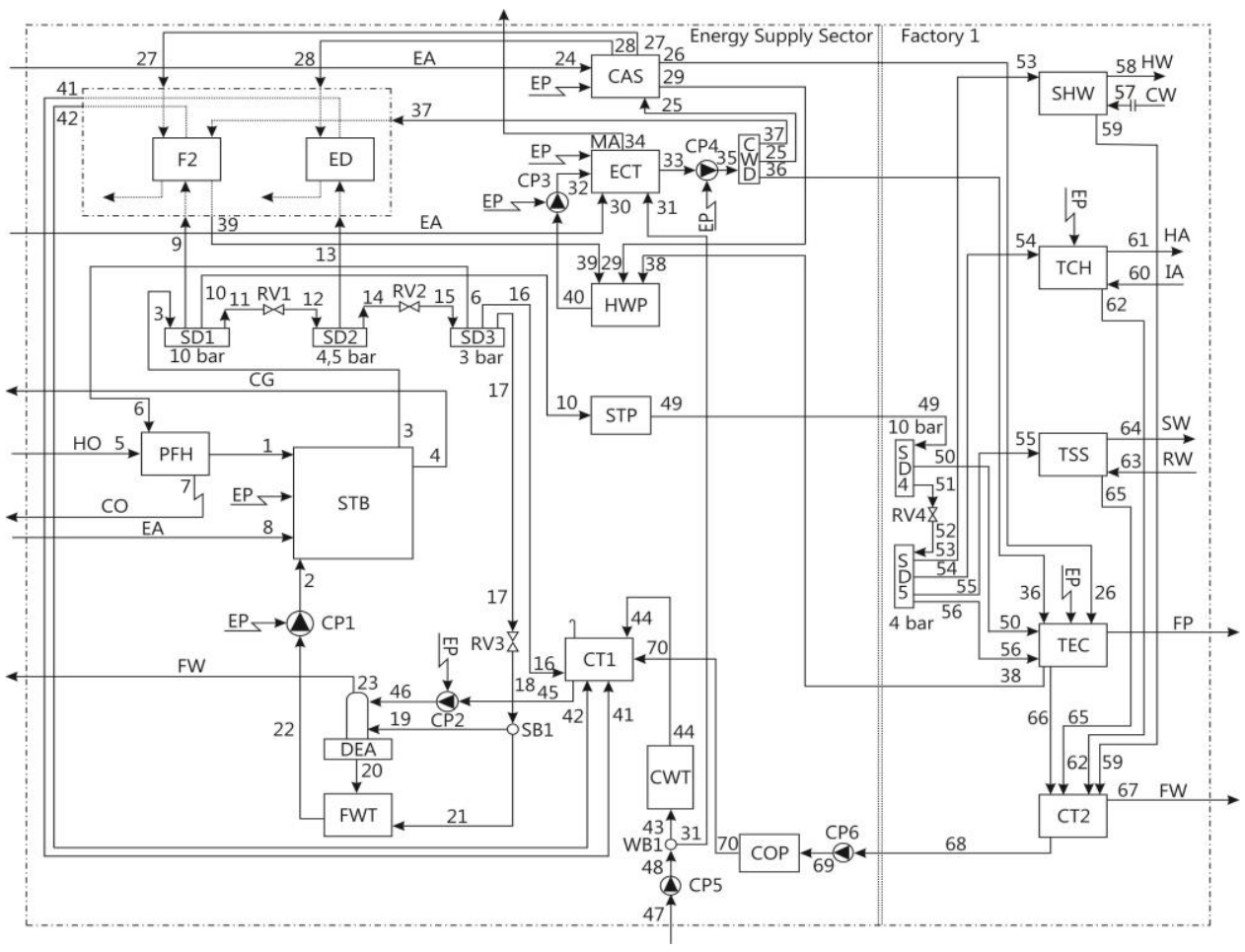

Fig. 1 Flow diagram of the representative industrial plant

Legend: CA - Compress Air, CG - Combustion Gasses, CO - Condensate, CP - Circulation Pump, CT - Condensate Tank, CW - Cold Water, EA - Environmental Air, ED - Engineering Department, EP - Electric Power, FW - Flash Water, FP - Factory Products, F2 - Factory 2, IA - Indoor Air, HA - Hot Air, HO - Heavy Oil, HW - Hot Water, MA - Moist Air, PF - Primary Fuel, RV - Reduce

Valve, RW - Return Water, SB - Steam Branch, SD - Steam Distributor, SW - Supply Water, WA - Waste Air, WB - Water Branch, CAS - Compress Air Station, COP - Condensate Pipeline, CWD

- Cold Water Distributor, CWT - Chemical Water Treatment, DEA - Deaerator, ECT - Evaporative Cooling Tower, FWT - Feed Water Tank, PFH - Primary Fuel Heating, STB - Steam Boiler, STP Steam Pipeline, SHW - Sanitary Hot Water, TCH - Thermal Comfort Hall, TEC - Technologic Consumers, TSS - Thermal Substation, HWP - Hot Water Pool

Electricity is used for the operation of the fans in the convectors. The total power of the fans is $19.2 \mathrm{~kW}$. In the thermal substation, the energy is transferred from the steam at pressure of 4 bars to hot water, which is used for the radiator heating system in the temperature regime $90 / 70^{\circ} \mathrm{C}$. Technology customers produce the final product. Technology consumers are using the steam at 10 and 4 bars. For technological reasons, the condensate at 4 bars is discharged into the sewer. The production technology requires the use of compressed air, which is rejected to the environment after use. Also, the cooling water in 
the factory is used for technological needs. During the production process, the temperature of cooling water increases. All consumers of the electricity in the factory, as well as technological consumers, are supplied with the electricity from a separate transformer station.

Factory 2 is supplied with the steam at pressure of 10 bars. The condensate from Factory 2 returns to the condensate tank 1.

The Engineering Department requires steam at 4 bars. The condensate from the Engineering Department is returned to the condensate tank in the full amount.

In this paper, we have discussed in detail Factory 1. The effects of Factory 2 and the part that deals with the Engineering Department should be considered on the basis of real values of the superheated steam that they use. The representative system of the considered rubber factory is mathematically modeled with 33 components $(k)$ and 70 streams $(j)$.

\section{SPLITTING THE TOTAL EXERGy DESTRUCTION INTO ENDOGENOUS AND EXOGENOUS PARTS OF EXERGY DESTRUCTION}

Conventional exergetic analyses pinpoint components and processes with high irreversibility $[1,5]$. The total exergy destruction occurring in a component does not result exclusively from the component but is also caused by the inefficiencies of the remaining system components.

A part of the exergy destruction within a system component is generally caused by the inefficiencies of the remaining system components (exogenous exergy destruction). If no irreversible processes and exergy losses occur in all remaining system components, the exergy destruction is due exclusively to the component being considered (endogenous exergy destruction). The total exergy destruction within a $k$-th component $E_{\mathrm{D}, k}$ is the sum of these two parts of exergy destruction [6]:

$$
\dot{E}_{D, k}=\dot{E}_{D, k}^{E N}+\dot{E}_{D, k}^{E X}
$$

where $\dot{E}_{D, k}^{E N}$ and $\dot{E}_{D, k}^{E X}$ endogenous and exogenous exergy destruction for $k$-th component, respectively.

The endogenous exergy destruction for $k$-th component is determined when this component operates under real conditions and all other components of the process are considered to operate without irreversibility (theoretically). The real and theoretical conditions for the most important components in the present industrial plant are shown in Table 1 [7]. When the endogenous part of exergy destruction of $k$-th component is known, the exogenous part of exergy destruction is obtained with Eq. (1).

A change in the exergy destruction in one subsystem generally affects the exergy destruction in other sub-systems, too [8]. Thus, the change in the total exergy input to a system is usually different from the change in the exergy destruction in one system component [9]. In complex thermal systems, it is very difficult and time consuming to separate these two parts of exergy destruction within a system component. To better understand the interactions among components, the exogenous exergy destruction within $k$-th component is also split. The sum of all the terms is lower than the exogenous exergy destruction within $k$-th component. The difference is caused by the simultaneous interactions of all (n-1) components. This difference is call mexogenous exergy destruction, but it is not of interest in this paper. Exergetic analysis is used to evaluate the performance of energy 
systems from thermodynamic aspect [10]. The essence of the exergetic analysis is that it provides information about the quality of energy [11].

Table 1 Diffusion coefficient and standard source term

\begin{tabular}{|c|c|c|c|c|c|}
\hline Component & Real condition & Theoretical cond. & Component & Real condition & Theoretical cond. \\
\hline STB & $\eta=90 \% ; \dot{Q}_{L} \neq 0$ & $\eta=100 \% ; \dot{Q}_{L}=0$ & HWP & $p_{j}, T_{j} \neq c t ; \dot{Q}_{L} \neq 0$ & $p_{j}, T_{j}=c t ; \dot{Q}_{L}=0$ \\
\hline PFH & $\begin{array}{l}\Delta T_{\min }>50 K \\
\dot{Q}_{L} \neq 0\end{array}$ & $\begin{array}{l}\Delta p^{\prime}=\Delta p^{\prime \prime}=0 \\
\eta=100 \% ; \dot{Q}_{L}=0\end{array}$ & $\begin{array}{l}\text { STD \& } \\
\text { CWD }\end{array}$ & $\begin{array}{l}p_{j} \approx c t ; T_{j} \neq c t \\
\dot{Q}_{L} \neq 0\end{array}$ & $\begin{array}{l}p_{j}=c t ; T_{j}=c t \\
\dot{Q}_{L}=0\end{array}$ \\
\hline DEA & $\begin{array}{l}p_{j} \approx c t \\
T_{20}>T_{46} ; T_{19}>T_{23}\end{array}$ & $\begin{array}{l}p_{j}=c t ; T_{j}=c t \\
\dot{Q}_{L}=0\end{array}$ & CT $(1 \div 2)$ & $\begin{array}{l}p_{j} \neq c t ; T_{j} \neq c t \\
\dot{Q}_{L} \neq 0\end{array}$ & $\begin{array}{l}p_{j}=c t ; T_{j}=c t \\
\dot{Q}_{L}=0\end{array}$ \\
\hline FWT & $\begin{array}{l}p_{j} \approx c t ; T_{j} \neq c t \\
\dot{Q}_{L} \neq 0\end{array}$ & $\begin{array}{l}p_{j}=c t ; T_{j}=c t \\
\dot{Q}_{L}=0\end{array}$ & SHW & $\begin{array}{l}\Delta T_{\min }>70 K \\
\dot{Q}_{L} \neq 0\end{array}$ & $\begin{array}{l}\Delta p^{\prime}=\Delta p^{\prime \prime}=0 \\
\eta=100 \% ; \dot{Q}_{L}=0\end{array}$ \\
\hline $\mathrm{CP}(1 \div 5)$ & $\eta=80 \%$ & $\eta=100 \%$ & $\mathrm{TCH}$ & $\Delta T_{\min }>70 K$ & $\eta=100 \%$ \\
\hline CAS & $\eta=90 \%$ & $\begin{array}{l}\eta=100 \% ; \dot{Q}_{L}=0 \\
T_{26}=T_{24} ; T_{29}=T_{26}\end{array}$ & TSS & $\begin{array}{l}\Delta T_{\text {min }}>60 K ; \\
\dot{Q}_{L} \neq 0\end{array}$ & $\begin{array}{l}\Delta p^{\prime}=\Delta p^{\prime \prime}=0 \\
\eta=100 \% ; \dot{Q}_{L}=0\end{array}$ \\
\hline
\end{tabular}

\section{RESULTS AND DISCUSSION}

Each segment of the system shown in Fig. 1 is separately analyzed and mass, energy and exergy balances are defined for each component. The results of the thermodynamic (mass flow rate $m_{j}$, specific enthalpy $h_{j}$ and specific entropy $s_{j}$ ) and exergetic analysis (exergy flow rate $E_{j}$ ) for the selected steams $j$ are presented in Table 2. Input data for the calculation are pressures $p$ and temperatures $t$ in different points of the flows of streams obtained from the existing process of the referent plant. The official data on the lower heating values for the fuel are used.

For solving the defined mathematical model, based on the equations in paragraph 2, a specialized software package, called Engineering Equation Solver, is used. The results of exergetic analysis at the component level are presented in Table 3.

Having in mind that the reduce valves typically serve other elements, the reduce valve and the component it serves should be considered together [7]. In the manner of conventional exergetic analysis, exergy of fuel $E_{\mathrm{F}, k}$ and product $E_{\mathrm{P}, k}$, exergy destruction $E_{\mathrm{D}, k}$, exergetic efficiency $\varepsilon_{k}$, maximal exergetic efficiency $\varepsilon^{\max }{ }_{k}$ and exergy destruction ratio $y_{\mathrm{D}}$ for the selected components are presented in this paper. Values of endogenous/exogenous exergy destruction are also presented for the selected components in the advanced exergetic analysis. Values of exergy of fuel, exergy of product, total exergy destruction and exergetic efficiency for overall system also presented in Table 3.

When evaluating any energy system, we mainly focus on its avoidable exergy destruction because it represents the potential for improvement. Components PFH, SHW, TCH and TSS have the high values of specific unavoidable exergy destruction of 1.706, 2.512, 2.754 and 1.152 , respectively. 
Table 2 Calculated variables for selected streams

\begin{tabular}{|c|c|c|c|c|c|c|c|c|c|c|c|c|c|}
\hline & $\dot{m}_{j}$ & $p_{j}$ & $t_{j}$ & $h_{j}$ & $s_{j}$ & $\dot{E}_{j}$ & & $\dot{m}_{j}$ & $p_{j}$ & $t_{j}$ & $h_{j}$ & $s_{j}$ & $\dot{E}_{j}$ \\
\hline & $\mathrm{kg} / \mathrm{s}$ & bar & ${ }^{\circ} \mathrm{C}$ & $\mathrm{kJ} / \mathrm{kg}$ & $\mathrm{kJ} / \mathrm{kgK}$ & $\mathrm{kW}$ & & $\mathrm{kg} / \mathrm{s}$ & bar & ${ }^{\circ} \mathrm{C}$ & $\mathrm{kJ} / \mathrm{kg}$ & $\mathrm{kJ} / \mathrm{kgK}$ & $\mathrm{kW}$ \\
\hline 1 & 0.05 & 4.01 & 80.00 & $-2,255.30$ & 2.207 & $2,412.10$ & 36 & 27.79 & 4.51 & 21.00 & 88.44 & 0.310 & 82.38 \\
\hline 2 & 0.86 & 10.29 & 103.00 & 432.41 & 1.340 & 34.26 & 37 & 8.50 & 4.51 & 21.00 & 88.44 & 0.310 & 25.20 \\
\hline 3 & 0.86 & 10.29 & 182.66 & $2,782.63$ & 6.584 & $1,117.55$ & 38 & 27.79 & 4.51 & 28.00 & 117.71 & 0.409 & 80.98 \\
\hline 4 & 1.47 & 3.51 & 180.00 & $-1,477.62$ & 7.038 & 238.53 & 39 & 8.50 & 4.51 & 27.00 & 113.53 & 0.395 & 24.47 \\
\hline 5 & 0.05 & 4.21 & 45.00 & $-2,323.15$ & 2.004 & $2,411.76$ & 40 & 41.80 & 1.01 & 27.41 & 114.91 & 0.401 & 106.20 \\
\hline 6 & 0.002 & 3.91 & 156.58 & $2,767.97$ & 6.975 & 2.29 & 41 & 02 & 1.01 & 80.00 & .97 & 075 & 0.43 \\
\hline 7 & 0.002 & 3.91 & 142.85 & 601.51 & 1.769 & 0.16 & 42 & 0.17 & 1.01 & 50.00 & 209.40 & 704 & 1.16 \\
\hline 8 & 1.41 & 1.01 & 21.00 & 40.77 & 5.755 & 0.04 & 43 & 0.83 & 1.01 & 12.01 & 50.52 & 0.181 & 3.09 \\
\hline 9 & 0.25 & 10.29 & 181.91 & $2,780.70$ & 6.580 & 325.78 & 44 & 0.48 & 1.01 & 12.01 & 50.52 & 181 & 1.79 \\
\hline 10 & 0.48 & 10.29 & 181.91 & $2,780.70$ & 6.580 & 626.11 & 45 & 0.82 & 1.01 & 80.00 & 334.97 & 1.075 & 17.56 \\
\hline 11 & 0.13 & 10.29 & 181.91 & $2,780.70$ & 6.580 & 165.09 & 46 & 0.82 & 1.51 & 80.01 & 335.03 & 75 & 17.60 \\
\hline 12 & 0.13 & 5.51 & 167.62 & $2,780.70$ & 6.852 & 154.81 & 47 & 0.83 & 1.01 & 12.00 & 50.46 & 0.180 & 3.09 \\
\hline 13 & 0.02 & 5.51 & 165.07 & $2,774.88$ & 6.839 & 24.40 & 48 & 0.83 & 1.51 & 12.00 & 50.52 & 0.180 & 3.13 \\
\hline 14 & 0.11 & 5.51 & 165.07 & $2,774.88$ & 6.839 & 130.17 & 49 & 0.48 & 10.29 & 181.91 & $2,780.70$ & 6.580 & 626.11 \\
\hline 15 & 0.11 & 3.91 & 159.74 & $2,774.88$ & 6.991 & 125.32 & 50 & 0.39 & 10.29 & 181. & $2,779.49$ & 6.578 & 514.57 \\
\hline 16 & 0.06 & 3.91 & 156.58 & $2,767.97$ & 6.975 & 75.38 & 51 & 0.08 & 10.29 & 181.44 & $2,779.49$ & 6.578 & 111.34 \\
\hline 17 & 0.04 & 3.91 & 156.58 & $2,767.97$ & 6.975 & 47.42 & 52 & 0.08 & 4.61 & 16 & $2,779.49$ & 6.929 & 102.39 \\
\hline 18 & 0.04 & 1.51 & 147.87 & $2,767.97$ & 7.405 & 42.25 & 53 & 0.01 & 4.61 & 160.30 & $2,770.86$ & 909 & 16.40 \\
\hline 19 & 0.01 & 1.51 & 147.87 & $2,767.97$ & 7.405 & 9.93 & 54 & 0.04 & 4.61 & 160 & $2,770.86$ & 6.909 & 45.06 \\
\hline 20 & 0.83 & 1.51 & 85.01 & 356.01 & 1.134 & 20.56 & 55 & 0.01 & 4.61 & 160.30 & $2,770.86$ & 6.909 & 16.79 \\
\hline 21 & 0.03 & 1.51 & 147.87 & $2,767.97$ & 7.405 & 32.31 & 56 & 0.02 & 4.61 & 160.30 & $2,770.86$ & 6.909 & 23.91 \\
\hline 22 & 0.86 & 1.51 & 102.88 & 431.26 & 1.339 & 33.43 & 57 & 0.12 & 6.51 & 12.00 & 50.99 & 0.180 & 0.53 \\
\hline 23 & 0.002 & 1.51 & 111.64 & $2,693.77$ & 7.220 & 2.52 & 58 & 0.12 & 6.31 & 60.00 & 251.67 & 0.831 & 1.37 \\
\hline 24 & 0.31 & 1.01 & 21.00 & 294.4 & 6.84 & 0.00 & 59 & 0.01 & 4.61 & 148.86 & 627.38 & 1.830 & 1.22 \\
\hline 25 & 5.51 & 4.51 & 21.00 & 88.44 & 0.310 & 16.33 & 60 & 3.68 & 1.01 & 18.00 & 291.40 & 6.836 & 0.31 \\
\hline 26 & 0.21 & 7.81 & 27.00 & 298.92 & 6.276 & 37.38 & 61 & 3.68 & 1.01 & 45.00 & 318.59 & 6.926 & 2.38 \\
\hline 27 & 0.10 & 7.81 & 27.00 & 298.92 & 6.276 & 17.47 & 62 & 0.04 & 4.61 & 148.86 & 627.38 & 1.830 & 3.34 \\
\hline 28 & 0.00 & 7.81 & 27.00 & 298.92 & 6.276 & 0.09 & 63 & 0.27 & 2.51 & 28.00 & 117.53 & 0.409 & 0.72 \\
\hline 29 & 5.51 & 4.01 & 24.50 & 103.03 & 0.360 & 15.44 & 64 & 0.27 & 2.31 & 55.00 & 230.42 & 0.768 & 2.27 \\
\hline 30 & 33.71 & 1.01 & 13.35 & 25.41 & 5.701 & 15.76 & 65 & 0.01 & 4.61 & 148.86 & 627.38 & 1.830 & 1.25 \\
\hline 31 & 35 & 1.01 & 12.01 & 50.52 & 0.181 & 1.30 & 66 & 0.02 & 4.61 & 148.86 & 627.38 & 1.830 & 1.77 \\
\hline 32 & 41.80 & 2.51 & 27.42 & 115.10 & 0.401 & 112.50 & 67 & 0.01 & 1.01 & 100.00 & $2,675.73$ & 7.354 & 2.89 \\
\hline 33 & 41.80 & 1.01 & 20.97 & 88.00 & 0.310 & 109.30 & 68 & 0.08 & 1.01 & 100.00 & 419.07 & 1.307 & 2.90 \\
\hline 34 & 34.06 & 1.01 & 21.35 & 60.06 & 5.821 & 6.46 & 69 & 0.08 & 1.01 & 100.00 & 419.07 & 1.307 & 2.90 \\
\hline 35 & 41.80 & 4.51 & 21.00 & 88.44 & 0.310 & 123.91 & 70 & 0.08 & 1.01 & 100.00 & 419.07 & 1.307 & 2.90 \\
\hline
\end{tabular}

Essentially, all the components are heat exchangers, whose design allows the use of only the physical exergy. In these components, the superheated steam is used as a primary fluid, and it has a great potential to perform useful work in chemical exergy. 
Table 3 Results of the exergetic analysis at the component level

\begin{tabular}{|c|c|c|c|c|c|c|c|c|c|}
\hline \multirow{3}{*}{$\begin{array}{l}\overline{\bar{D}} \\
\text { है } \\
\text { Z }\end{array}$} & \multirow{3}{*}{ K } & \multicolumn{3}{|c|}{ Conventional EA } & \multicolumn{2}{|c|}{ Splitting $E_{D}$} & \multicolumn{3}{|c|}{ EA evaluation } \\
\hline & & $\dot{E}_{F, k}$ & $\dot{E}_{P, k}$ & $\dot{E}_{D, k}$ & $\dot{E}_{D, k}^{E N}$ & $\dot{E}_{D, k}^{E X}$ & $\varepsilon_{k}$ & $\varepsilon_{k}^{\max }$ & $y_{D, k}$ \\
\hline & & $\mathrm{kW}$ & $\mathrm{kW}$ & $\mathrm{kW}$ & $\mathrm{kW}$ & $\mathrm{kW}$ & $\%$ & $\%$ & $\%$ \\
\hline 1 & STB & 185.50 & $1,053.29$ & $1,132.21$ & $1,097.6$ & 34.58 & 48.19 & 52.69 & 43.66 \\
\hline 2 & PFH & 2.13 & 0.34 & 1.79 & 1.58 & 0.21 & 15.96 & 36.96 & 0.07 \\
\hline 3 & DEA & 7.24 & 2.78 & 4.46 & 4.33 & 3 & 38.37 & 100.00 & 0.17 \\
\hline 4 & FWT & 46.87 & 33.43 & 13.44 & 4.24 & 9.20 & 71.32 & 100.00 & 0.52 \\
\hline 5 & $\mathrm{CP} 1$ & 0.98 & 0.83 & 0.15 & 0.15 & 0.00 & 84.42 & 96.03 & 0.01 \\
\hline 6 & $\mathrm{CP} 2$ & 0.05 & 0.04 & 0.01 & 0.01 & 0.00 & 75.92 & 94.70 & 0.00 \\
\hline 7 & SD1 & $1,117.55$ & $1,116.98$ & 0.57 & 0.58 & -0.01 & 99.95 & 100.00 & 0.02 \\
\hline $\begin{array}{l}8 \\
9\end{array}$ & $\begin{array}{l}\text { SD2 } \\
\text { RV1 }\end{array}$ & .09 & 7 & 10.52 & 6 & 4.06 & 3.63 & 93.79 & 0.41 \\
\hline $\begin{array}{l}10 \\
11\end{array}$ & $\begin{array}{l}\text { SD3 } \\
\text { RV2 }\end{array}$ & 130.17 & 125.09 & 5.08 & 2.80 & 28 & 6.10 & 96.28 & 0.20 \\
\hline 12 & STP & 626.11 & 626.11 & 0.00 & 0.00 & 0.00 & 100.00 & 100.00 & 0.00 \\
\hline 13 & CAS & 82.70 & 54.84 & 27.86 & 27.86 & 0.00 & 66.31 & 71.29 & 1.07 \\
\hline 14 & $\mathrm{CP} 3$ & 7.87 & 6.30 & 1.57 & 1.54 & 0.03 & 80.09 & 95.02 & 0.06 \\
\hline 15 & ECT & 32.83 & 4.80 & 28.03 & 22.75 & 5.28 & 14.62 & 81.52 & 1.08 \\
\hline 16 & HWP & 120.89 & 106.20 & 14.69 & 14.49 & 0.20 & 87.85 & 99.96 & 0.57 \\
\hline 17 & $\mathrm{CP} 4$ & 18.32 & 14.61 & 3.71 & 3.44 & 0.27 & 79.75 & 94.76 & 0.14 \\
\hline 18 & CWD & 123.91 & 123.91 & 0.00 & 0.00 & 0.00 & 100.00 & 100.00 & 0.00 \\
\hline 19 & CT1 & 79.61 & 15.51 & 64.10 & 63.55 & 0.55 & 19.48 & 100.00 & 2.47 \\
\hline 20 & CWT & 3.13 & 3.13 & 0.00 & 0.00 & 0.00 & 100.00 & 100.00 & 0.00 \\
\hline 21 & CP5 & 0.05 & & 0.01 & 0.00 & 0.01 & 77.01 & 100.00 & 0.00 \\
\hline 22 & SD4 & 626.11 & 625.91 & 0.20 & 0.00 & 0.20 & 99.97 & 100.00 & 0.01 \\
\hline $\begin{array}{l}23 \\
24\end{array}$ & $\begin{array}{l}\text { SD5 } \\
\text { RV4 }\end{array}$ & 111.34 & 102.16 & 9.18 & 8.44 & 0.74 & 91.75 & 100.00 & 0.35 \\
\hline 25 & SHW & 15.33 & 0.99 & 14.34 & 14.16 & 0.18 & 6.46 & 28.47 & 0.55 \\
\hline 26 & $\mathrm{TCH}$ & 60.92 & 2.07 & 58.85 & 58.76 & 0.09 & 3.40 & 26.64 & 2.27 \\
\hline 27 & TSS & 15.54 & 1.55 & 13.99 & 13.96 & 0.03 & 9.97 & 46.46 & 0.54 \\
\hline 28 & CT2 & 4.69 & 2.90 & 1.79 & 2.18 & -0.39 & 61.83 & 99.99 & 0.07 \\
\hline 29 & RV3 & 47.45 & 42.25 & 5.20 & 0.00 & 5.20 & 89.04 & 89.04 & 0.20 \\
\hline 30 & CP6 & 2.90 & 2.90 & 0.00 & 0.00 & 0.00 & 100.00 & 100.00 & 0.000 \\
\hline 31 & $\mathrm{COP}$ & 2.90 & 2.90 & 0.00 & 0.00 & 0.00 & 100.00 & 100.00 & 0.000 \\
\hline 32 & SB1 & 42.25 & 42.24 & 0.01 & 0.00 & 0.01 & 99.98 & 100.00 & 0.000 \\
\hline 33 & WB1 & 3.09 & 3.09 & 0.00 & 0.00 & 0.00 & 100.00 & 100.00 & 0.000 \\
\hline \multicolumn{2}{|r|}{ erall } & $2,582.59$ & 920.27 & $1,411.77$ & & & 35.90 & & \\
\hline
\end{tabular}

Value of exergy loss, $E_{\mathrm{L}, t o t}$, for overall system is $250.56^{\circ} \mathrm{kW}$.

However, that potential in these devices is not exploited. On the other hand, to obtain the superheated steam, a certain amount of primary fuel (resources) in the steam generator is consumed. 
Fig. 2 presents the values of the current and maximum exergetic efficiency at the component level. It is observed that the most significant limits in the values of the maximum exergetic efficiency are in the heat exchangers: steam-fuel, steam-water and steam-air, or in components SHW, TCH and TSS. These limits are caused by high levels of specific unavoidable exergy destruction in these components. In addition, in the steam generator, from the total exergy destruction of $1,132.21^{\circ} \mathrm{kW}, 83.53 \%$ is unavoidable, and even $96.94 \%$ of destroyed useful work comes from internal irreversibility in the component.

Therefore, exergetic efficiency higher than $52.69 \%$ cannot be achieved in the steam generator.

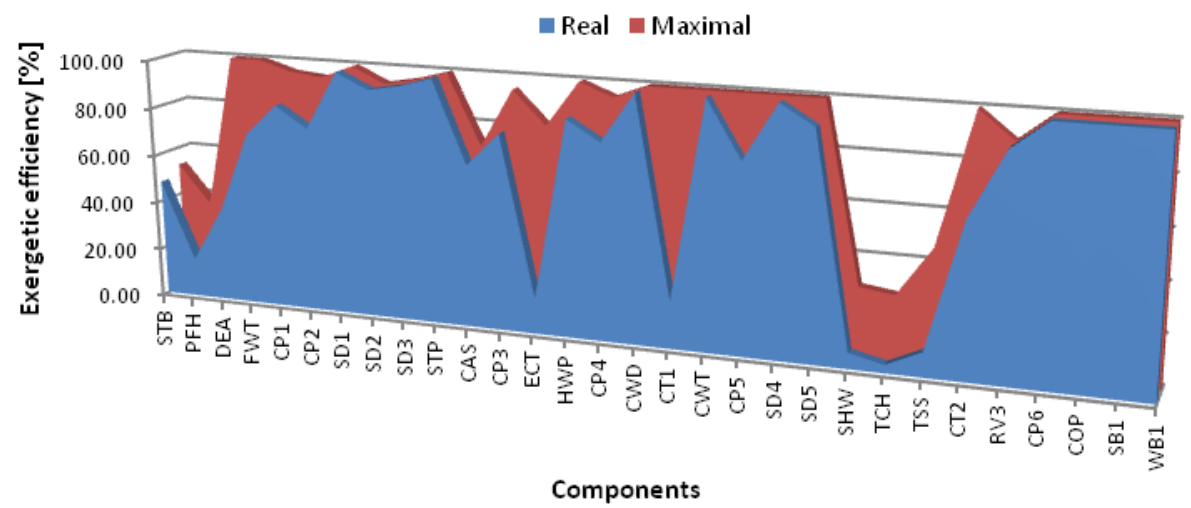

Fig. 2 Real and maximal exergetic efficiency

The exergetic efficiency of the total plant indicates that some potential exists for the improvement of the overall efficiency and reduction of costs, see Table 3. Exergy losses are mainly associated with the exhaust gases as well as the exergy transfer to the environment. From the total exergy losses, the loss of exhaust gas is $95.19 \%$ or $238.53^{\circ} \mathrm{kW}$. All exergy losses account together for $10.39 \%$ or $250.56^{\circ} \mathrm{kW}$ of the fuel exergy supplied to the overall plant. In the plant, the components destroyed $58.53 \%$ of the fuel exergy, or $1,411.77^{\circ} \mathrm{kW}$.

The compressed air station has a higher improvement potential, $22.08^{\circ} \mathrm{kW}$ or $79.25 \%$. In the compressed air station, the entire amount of destroyed useful work comes from inside ireversibilities (endogenous exergy destruction $27.86^{\circ} \mathrm{kW}$ ). Exergy destruction in the deaerator is mainly caused by differences in temperature and pressure of the water streams being mixed. In the deaerator more than $97 \%$ or $4.33^{\circ} \mathrm{kW}$ comes from irreversibilities in the component and $2.92 \%$ from the other components.

Fig. 3 presents the total, endogenous and exogenous exergy destruction of the components of the energy system. It is observed that the steam generator has the dominant effect. However, from Fig. 3 we can unequivocally conclude that $1,097.63^{\circ} \mathrm{kW}$ or $96.95 \%$ from the total exergy destruction of the steam generator comes from the internal irreversibility in components, while the influence of other components of destroyed useful work in the steam generator amounts only to $3.05 \%$, or $34.58^{\circ} \mathrm{kW}$. Significantly, this $34.58^{\circ} \mathrm{kW}$ of destroyed work capacity is the highest value among all the external exergy destruction in the energy system (Fig. 3 and Table 2). 
Fig. 3 shows that the exergy destruction in components CT1, TCH, ECT and CAS is not so small, but the loss of ability originates primarily from the internal irreversibility of the components.

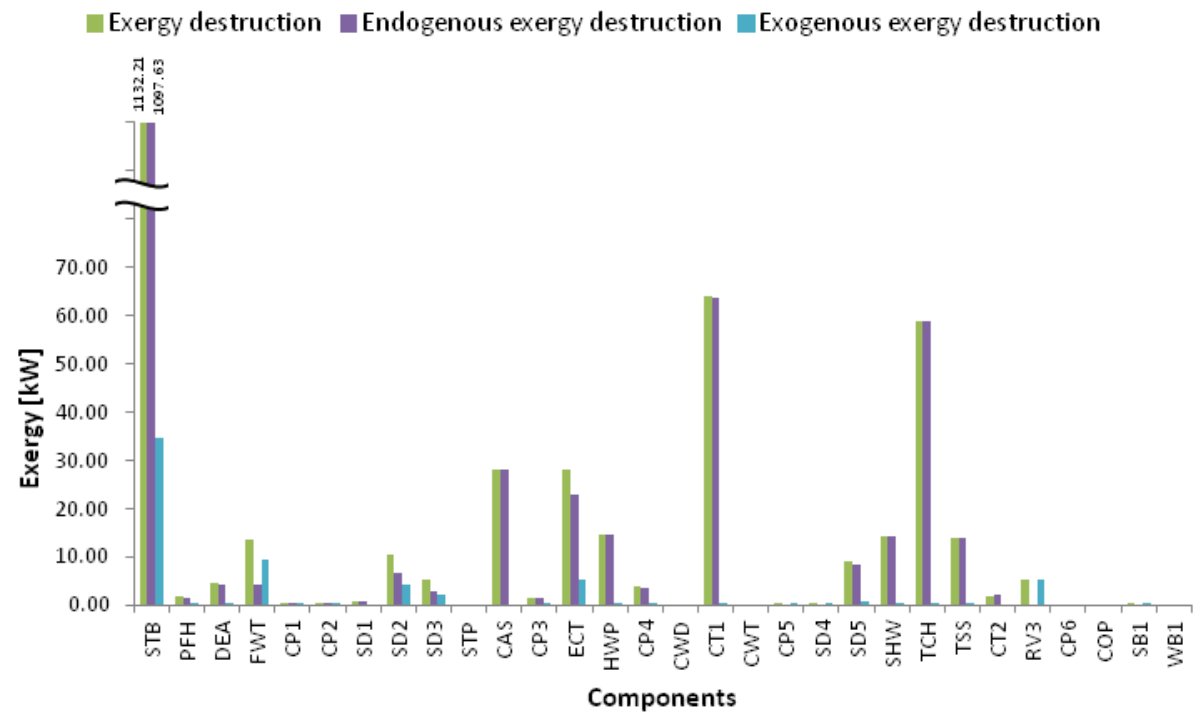

Fig. 3 Endogenous and exogenous exergy destructions

\section{CONCLUSIONS}

The results of the conventional exergetic analysis are strongly supplemented by the advanced exergetic analysis. Irreversibilities identified in the conventional exergetic analysis have been split, according to their origins, in the advanced exergetic analysis.

This paper presents the results of the splitting of the total exergy destruction into endogenous and exogenous parts for a real complex industrial plant. The highest exergy destruction is caused by the steam boiler. More than $80 \%$ of the total exergy destruction of the overall system comes from the boiler. Using the method presented in this paper we know that almost $97 \%$ of the total exergy destruction within this component results from the operation of the component itself (endogenous exergy destruction). The advanced exergetic analysis undoubtedly ranks the improvement priority of the steam boiler first, followed by the thermal comfort of the hall and the thermal substation.

The combined splitting in advanced exergetic analysis will be investigated in the next step of this study. 


\section{REFERENCES}

1. Kelly, S., Tsatsaronis, G., Morosuk, T., 2009, Advanced exergetic analysis: Approaches for splitting the exergy destruction into endogenous and exogenous parts, Energy, 34(3), pp. 384-391.

2. Frangopoulos, C.A., (Editor), 2009, Exergy, energy system analysis and optimization, 1, EOLSS, Oxford, United Kingdom, 292 .

3. Celador, A.C., Iribarren E.P., Lizarraga J.M., Valdes L.A., 2011, The Thermoeconomic analysis of a microCHP installation in a tertiary sector building through transient simulation, Proc. of International Conference ECOS 2011, pp. 2958-2971, Novi Sad, Serbia.

4. Bejan, A., Tsatsaronis, G., Moran, M., 1996, Thermal design \& optimization, John Wiley \& Sons, Inc, New York, USA, $542 \mathrm{p}$.

5. Petrakopoulou F, Tsatsaronis G., Morosuk T., Carassai A., 2012, Conventional and advanced exergetic analyses applied to a combined cycle power plant, Energy, 41(1), pp. 146-152.

6. Erbay, Z., Hepbasli, A., 2014, Application of conventional and advanced exergy analyses to evaluate the performance of a ground-source heat pump (GSHP) dryer used in food drying, Energy Conversion and Management, 78, pp. 499-507.

7. Vučković, G., 2013, Examination of energy efficiency of a complex energy plant by applying the method of exergoeconomics, (in Serbian), PhD Thesis, University of Niš, Faculty of Mechanical Engineering, Niš, Serbia, $247 \mathrm{p}$.

8. Moran, M., Shapiro, H., 2006, Fundamentals of engineering thermodynamics, John Wiley \& Sons, Ltd, West Sussex, England, $831 \mathrm{p}$.

9. Szargut J., Morris D., Steward F., 1988, Exergy Analysis of thermal, chemical, and metallurgical processes, New York: Hemisphere Publ. Corp, 332 p.

10. Gungor A., Tsatsaronis G., Gunerhan H., Hepbasli A., 2015, Advanced exergoeconomic analysis of gas engine heat pump (GEHP) for food drying processes, Energy Conversion and Management, 91, pp. 132-139.

11. Pandey A.K., Pant P.C., Sastry O.S., Kumar A, Tyagi S.K., 2013, Energy and exergy performance evaluation of a typical solar photovoltaic module, Thermal Science, doi:10.2298/TSCI130218147P. 